\title{
EDITORS’ NOTE
}

\section{Tribute to Jonna Barry}

This will be the final issue of Wilderness \& Environmental Medicine with our Managing Editor, Jonna Barry. Jonna has been the cornerstone of WEM since she arrived to the Wilderness Medical Society in 1999. The growth and development of the Journal over the past 15 years are largely a product of her hard work and dedication.

The Wilderness Medical Society had recently moved from Indianapolis to Colorado Springs when Jonna answered a newspaper ad for a "publications coordinator" for a medical journal in March 1999. Her first issue of WEM was Volume 10.2; it was 65 pages (Figure 1). Bill Robinson was serving as the Editor-in-Chief (EIC). At the end of that first year, Jonna reported a total of 38 manuscript submissions in the annual report to the board. $W E M$ was established, but still very much in its early stages.

Jonna was also recruited to assist with the Wilderness Medicine magazine, then known as the Wilderness Medicine Letter with Karl Neumann as Editor. The first issue she worked on was Volume 16.3, Summer 1999. The format was a simple 2-color, 20-page selfcover newsletter (Figure 2).

In early 2003, Jonna was given the title of Managing Editor. She oversaw all things associated with WEM and Wilderness Medicine Letter, including writing, editing, proofreading, database management, manuscript tracking, production schedule development and adherence, advertising, art direction, photo management and selection, mailing list management, and all correspondence. These were the "old days" where $98 \%$ of all correspondence was done through the post office rather than email. WEM proofs were printed on oversized hardcopy galley sheets that literally papered the office.

Jonna also wrote and produced meeting brochures, advertising pieces, and spearheaded the 2003 project to refresh and redesign the WMS logo. Over the years, she became the Managing Editor for the Educational Presentation Series (Editors: Luanne Freer, Brad Bennett, Mel Otten), Community Education Lectures (Editor: Deb Stoner), and the WMS Teaching Scenarios (Editor: Jay Lemery).

Bob Norris was appointed the EIC of the Journal in 2001. In 2003, Jonna assisted with a top to bottom redesign - including the addition of color printing and photos. The Journal grew exponentially in submissions, size, and readership. When Scott McIntosh became EIC in 2010, two Associate Editors were added - Tracy Cushing and Linda Keyes - to keep up with the increased submissions and reviews.

The WM Letter eventually became the 4-color Wilderness Medicine Magazine when Christopher Van Tilburg became Editor-in-Chief in the Spring of 2003. By 2011, the magazine went online, in addition to hard copy. Then in 2013 Jonna helped take the magazine to the next level a new online format where it remains today - with beautiful photos, a streamlined and interactive format, and constantly changing articles and information.

It became clear to her in the fall of 2013 that the Magazine and Journal had outgrown one Managing Editor

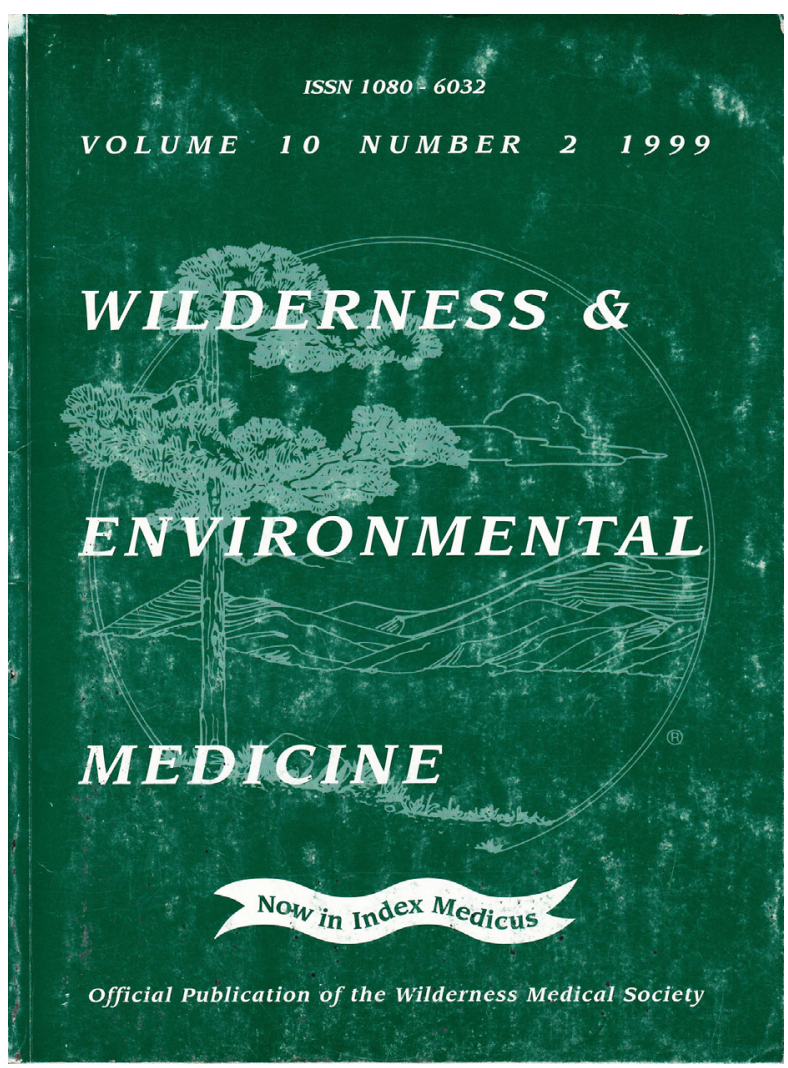

Figure 1. Wilderness \& Environmental Medicine, 1999. 


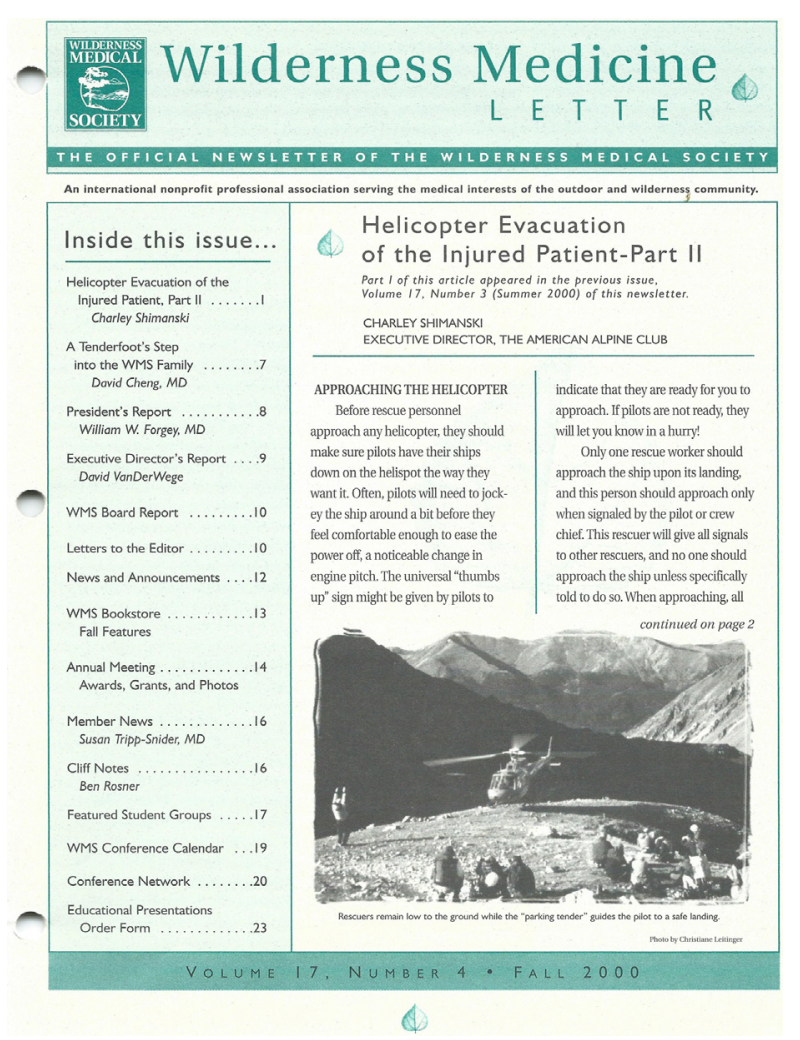

Figure 2. The Wilderness Medicine Letter, 2000.

for both publications. Jonna remained with WEM, while Ryan Ingwersen took the helm of the online magazine.

Jonna humbly states, "It was never a one-woman show though...it actually took a village, including my exceptional WMS coworkers, editors, section editors, reviewers, writers, researchers, and designers. It has been a great and fulfilling run, and a true privilege to work with so many talented and whip-smart people." We feel the same way about working with her.

Whenever we arrived at a WMS conference, Jonna would be the first to greet us with a smile and hug. When we Editors had a question about style, Jonna would have the answer. Whenever we were nervous about filling an issue, Jonna would assure us that we were "ok." Jonna's personal knowledge about both the day-to-day workings of the Journal as well as the quirks and qualities of all the reviewers and editors has been invaluable, and will be difficult to replace. Whether it was sliding in an editorial piece past the deadline, or finding an expert on esoteric insect venoms, Jonna knew how to get it done. She carefully selected reviewers for every submitted manuscript and tirelessly saw them through from revision to publication. She has assembled each and every issue of WEM with modesty, and always with a positive attitude and a smile.
We therefore dedicate this issue of WEM to Jonna Barry. We wish her the very best in retirement and we say good-bye with sadness and gratitude. Since our thanks alone are not enough, we have also asked the previous editors to provide their tributes. The wilderness medicine community and WEM will miss you, Jonna.

\section{Scott E. McIntosh, MD, MPH Editor-in-Chief Tracy Cushing, MD, MPH Associate Editor Linda Keyes, MD Associate Editor}

They say the only constant in life is change. Some changes, of course, are bigger than others, and Wilderness \& Environmental Medicine is undergoing one of the biggest in recent years with the well-deserved retirement of Jonna Barry as Managing Editor for the Journal. When I was asked to take on the Editor-in-Chief position for WEM in 2001, I was more than a bit anxious about the workload that was being added to my plate. But I knew, from my prior work with the Journal, that I could count on Jonna to help me learn the ropes, and keep my work organized and prioritized. As I have said many times, Jonna has been a stabilizing force for the Journal for all the years she has served. Besides overseeing day-to-day journal operations, she has helped WEM successfully navigate major milestones such as changes in publishers and editors, the launch of our webbased manuscript management system, changes in journal format and design, the offering of continuing medical education credits for each issue, and many more. In addition, she has planned and overseen our annual Publications Committee and Editorial Board meetings at our annual conferences (ie, a proverbial "herding of cats"). I can never thank Jonna enough for all she meant to me during my tenure with the Journal, and I am proud to still call her a dear friend. I wish her all the best in her retirement - time with her wonderful family and time to stop and smell the wild flowers. She has earned it!

Robert L. Norris, MD

Editor-in-Chief, 2001-2010

Serving as Editor-in-Chief of a medical journal is only possible with tremendous support. Having closely watched the wonderful evolution of Wilderness \& Environmental Medicine since the first issue in 1990 of its predecessor Journal of Wilderness Medicine, there's no doubt that Jonna Barry has long been its guiding light. WEM has been transformed under her graceful expertise into the leading periodical in the field of 
wilderness medicine, and much of the credit for the journey goes to Jonna. She is always thoughtful, organized, and insightful. Without her, the Journal would not be where it is today; she has contributed as much as anyone to the foundation and energy that will carry it into the future. Jonna set the bar high for whomever follows her, and knowing her, she'll be the first to step forward and offer to help. Thank you, Jonna. We couldn't have done it without you.

Paul S. Auerbach, MD, MS

Founding Co-Editor, Journal of Wilderness Medicine 